\title{
O IMAGINÁRIO MÍTICO INDÍGENA E AFRICANO - COSMOGONIAS E OUTRAS CRIAÇÕES IMAGINÁRIAS - NA LITERATURA E NAS ARTES.
}

\author{
Carlos Augusto de Melo (UFU) ${ }^{1}$ \\ ORCID: https://orcid.org/0000-0001-9305-9519 \\ Zuleide Duarte (UEPB) ${ }^{2}$ \\ ORCID: https://orcid.org/0000-0002-9378-5921
}

Foi Omama que criou a terra e a floresta, o vento que agita suas folhas e os rios cuja água bebemos. Foi ele que nos deu a vida e nos fez muitos. Nossos maiores nos deram a ouvir seu nome desde sempre. No começo, Omama e seu irmão Yoasi vieram à existência sozinhos. Não tiveram pai nem mãe. Antes deles, no primeiro, havia apenas a gente que chamamos yarori. Esses ancestrais eram humanos com nomes de animais e não paravam de se transformar. Assim, foram aos poucos se tornando os animais de caça que hoje flechamos e comemos. (...) Isso ouvi os antigos contarem.

Retirado da ilustre obra A Queda do Céu (2015), de Bruce Albert e Davi Kopenawa Yanomami, o trecho acima introduz uma das instigantes narrativas cosmogônicas dos yanomami brasileiros contadas do ponto de vista indígena do xamã Davi Kopenawa, cujas lembranças inscritas em suas memórias são originárias de relatos que as(os) anciãs(ãos) foram transmitindo oralmente ao seu povo, em contextos atemporais, outorgando-lhes, assim, um modo coerente e integrado de perceberem o mundo e se colocarem nele enquanto identidades coletivas que demarcam seus espaços culturais étnicos próprios. Aqui, nesta introdução, importa apreender dessa experiência de alteridade com as palavras de Kopenawa que, em sua imensidade, diversificação e pluralidade - e, portanto, não circunscritos a uma ideia homogênea e unificante acerca das culturas dos povos originários - os imaginários indígenas são grandes potências criativas de representações ontológicas e fenomenológicas humanas acerca da realidade, as quais emergem de processos coletivos, orais, sagrados e ancestrais. Para o escritor indígena Kaká Werá Jecupé, os povos originários classificam “a realidade como uma pedra de cristal lapidado, com muitas faces. (...) Para serem descritas,

\footnotetext{
${ }^{1}$ Professor de Literatura na Universidade Federal de Uberlândia (UFU). Doutorado em Teoria e História pela Unicamp. Possui pesquisa em revisões do cânone, historiografia literária, literaturas indígenas.

${ }^{2}$ Professora de Literatura na Universidade Estadual da Paraíba (UEPB), Campina Grande. Doutorado em Letras pela Universidade Federal da Paraíba e Pós-Doutorado pela Universidade Federal do Rio Grande do Sul. Tem trabalhos publicados em livros e revistas internacionais. Sua última publicação é a obra Índice de autoras das literaturas africanas de língua portuguesa (Parábola, 2021).
} 
é necessário ativar o encanto para imaginarmos como são as faces que não se expressam por palavras.” (JECUPÉ, 2020, p. 71).

Essas construções simbólicas demonstram, em estruturas discursivas que o Ocidente normatizou como mitos, cosmovisões que estabelecem os elementos das realidades cognitiva, afetiva e espiritual dos povos originários, em suas singularidades, relacionandoos a contextos de produção específicos. De modo geral, para as teorias ocidentais, trata-se de mitos e/ou lendas nos quais se estruturam formas criativas de conhecimento identitário e cultural com as quais diversas sociedades originárias, espalhadas pela imensidão territorial do mundo, puderam (re)elaborar e (res)significar suas existências, interpretando a origem do mundo, dos fenômenos naturais e da vida humana em toda sua complexidade. Como ressalta Rocha, os mitos são uma "forma de as sociedades espelharem suas contradições, exprimirem seus paradoxos, dúvidas e inquietações. Pode ser visto como uma possibilidade de se refletir sobre a existência, o cosmos, as situações de 'estar no mundo' ou as relações sociais." (ROCHA, 2006, p. 7). Contudo, esses textos imaginativos não se reduzem a essas categorizações cartesianas ocidentais, uma vez que são expressões mnemônicas incorporadas nas experiências da contação de história pela oralidade, dos grafismos, dos movimentos e rituais, configurando-se, conforme palavras de Kaká Werá Jecupé (2020, p. 71), em "um jeito de narrar outras realidades ou contrapartes do mundo em que vivemos".

É importante ressaltar que essas práticas imaginativas não são específicas dos povos originários, uma vez que outros grupos étnicos as valorizam, geralmente os que mantêm relações subjacentes com as suas tradições e ancestralidades, cujas(os) enunciadoras(es) sabem, como apontou Viveiros de Castro (2015, p. 15) a respeito do discurso de Kopenawa, "qual é, onde é, o que é o seu lugar." Em se tratando do território brasileiro, além dos indígenas, os povos africanos ou afrodescendentes elaboraram suas cosmogonias e outras criações que, até hoje, frequentam o território do sagrado e "portanto, é uma 'história verdadeira', porque sempre se refere a realidades.” (ELIADE, 2006, p. 12). Reginaldo Prandi (2001, p. 26) afirma que “os valores e ritos” das religiões dos orixás africanos, por exemplo, "repousam num conhecimento mítico".

No entanto, a partir de um viés epistemológico eurocêntrico e deliberadamente etnocida, os colonizadores interessaram-se em compreender e registrar as cosmovisões africanas e ameríndias como uma violenta estratégia política de dominação e colonização do saber. Os imaginários ameríndios, africanos e, também, afro-brasileiros, registrados em 
escrita alfabética ocidental, começaram a ser "ameaçados pelas tentativas dos brancos de aculturá-los" (POTIGUARA, 1989, s/p), prevalecendo a centralidade do ponto de vista colonizador que reproduz uma perspectiva de mundo dominadora no encontro com o Outro. Ao longo da colonialidade, os imaginários cosmogônicos desses povos subalternizados foram sendo reproduzidos, traduzidos e remodelados, adquirindo, na maioria das vezes, feições estereotipadas, pejorativas e/ou folclorizadas, as quais, aos poucos, a serviço dos nacionalismos, passaram a ser inseridas nos imaginários da sociedade capitalista até a nossa contemporaneidade.

No Brasil, em se tratando de Exu, orixá das culturas iorubás, Reginaldo Prandi menciona que, na "época dos primeiros contatos de missionários cristãos com os iorubas na África, Exu foi grosseiramente identificado pelos europeus com o diabo e ele carrega esse fardo até os dias de hoje.” (PRANDI, 2001, p. 21). A escritora indígena Eliane Potiguara (2019, p. 143) afirma que viu centenas de "pessoas escreverem sobre as lendas indígenas, alterando o conteúdo do texto, o final da história. Escritores que não eram indígenas, que pegavam um mito e alteravam para um texto escrito. Muda tudo. Não pode ser mudado. Aquilo é feito por indígena, alguém tem de defender esse território." Nesse contexto do colonialismo, os imaginários indígenas, africanos e afro-brasileiros foram sendo interpretados, à revelia de seus povos, pela ótica ocidental, como fontes antropológicas e literárias, e chegaram ao circuito cultural, ao mercado editorial, às escolas, inscrevendo-se nas memórias das(os) brasileiras(os), como criações cosmogônicas nacionais.

Por muito tempo, essa postura hegemônica diante dos saberes não ocidentais silenciou as vozes que poderiam nos contar sobre suas leituras simbólicas do mundo a partir do próprio mundo em que viviam e das epistemes que lhes eram próprias. Todavia, na contracorrente desse legado colonial perverso, assumindo seus direitos de fala, ocupando seus lugares nas artes e literaturas institucionais, muitas(os) indígenas, africanas(os) e afrobrasileiras(os) têm sido protagonistas nas lutas pelos direitos de narrar suas cosmovisões e seus imaginários ancestrais e tradicionais, com o intuito de que sejam ressignificados por perspectivas étnicas e identitárias em se considerando seus lugares de fala. Esse ato político contribui exemplarmente para situações de agenciamento desses sujeitos contra os usos e abusos históricos que os Outros fizeram de seus modos de se perceberem no mundo, relacionarem-se com seus territórios, sagrados e míticos, e lidarem com suas existências étnicas. 
As literaturas indígenas, assim como as literaturas africanas e afro-brasileiras, têm em suas matrizes formas de resistência, denúncia e militância política. Refugiar-se na imaginação, na fé dos deuses ancestrais, na força do verbo oral, na contação de histórias, na força da natureza, como motivação literária para se deixar ecoar o grito de revolta e força contra a opressão da colonialidade. No Brasil, os afrodescendentes negros e os indígenas também lutaram e ainda o fazem contra a vertente perversa do colonialismo: o racismo. Os(as) autor(as) negro(as) e indígenas desafiam o bloco fechado da cultura de herança europeia e branca, criando meios de divulgação e visibilidade de suas produções culturais e literárias. Vale aqui registrar ações pioneiras como as das(os) escritoras(os) negras(os) Abdias Nascimento (1914-2011), Carlos Assumpção (1923-), Carolina Maria de Jesus (1914-1977), Conceição Evaristo (1946-), Geni Guimarães (1947-), Solano Trindade (19081974), bem como as das(os) escritoras(os) Eliane Potiguara (1950-), Airton Krenak (1953), Daniel Munduruku (1964-), entre tantas e tantos outras(os).

Trata-se de literaturas que são produzidas pelo prazer estético, mas também se voltam para o coletivo social em uma dinâmica decolonial e anticolonial. Sendo assim, os(as) escritor(as) indígenas, africanos(as) e afro-brasileiras(os), sejam homens ou mulheres, abarcando os diversos gêneros literários, quando escrevem não veem a literatura como apenas uma inserção em um nicho minoritário, escrevem para se fazerem ouvir, para darem voz às(aos) outras(os), denunciando as dificuldades enfrentadas. Elas(es) têm como meta essencial visibilizar (torna visível) e dizibilizar (produz formas de dizer) o Outro, dando-lhe a palavra, ao mesmo tempo em que denunciam e resistem às adversidades tanto sociais, quanto no meio literário. Essa reivindicação por visibilidade e reconhecimento no espaço literário tem a ver com o que Ailton Krenak interpreta sobre o porquê de negros e indígenas reivindicarem espaços urbanos que, possivelmente, podem contrariar a lógica do colonizador, uma vez que:

o pessoal reivindica espaço, mas acho que é menos do espaço físico e mais o reconhecimento, ter voz. O grande reclamo é menos por coisas e mais por visibilidade, voz. Quando dizem que os negros são invisíveis, ou os índios na nossa sociedade, eu digo que a mobilização dos negros e dos índios é por visibilidade. Menos por acesso a coisas, as que dão o poder, que são efetivas formas de representação do poder político, que é acesso, domínio, controle sobre áreas, territórios, bem materiais, e tal. Juntos reivindicam menos o acesso a esses lugares físicos e mais a esses lugares simbólicos de reconhecimento. (KRENAK, 2019, p. 28-29). 
Ao nos debruçarmos sobre mitos, tradições e rituais africanos, por exemplo, encontramos cosmologias filiadas a uma ancestralidade oriunda da África profunda, variando apenas em consonância com os grupos étnicos que para o Brasil vieram. Dependendo da "nação" da qual se originaram, nos cultos, surgem Olorum, que ordenou a criação de Ifé, a terra, e da união entre Olorum e Olocum nasceram Obatalá e Odudua. A partir de então, uma série de eventos explicará a origem do homem na terra. O panteão utilizado nas religiões afrodescendentes rende cultos aos deuses (orixás) também reverenciados na África negra. Da região de Orubalândia, na Nigéria, vem Ogun, Oxum, Afo Oba, Iemanjá, entre outros, deidades que nomeiam a natureza. Entre fauna, flora e fenômenos naturais, os diálogos e as invocações com um outro plano se estabelece, indicando uma ligação entre um mundo dito visível e outro, ou outros, das origens, dos ancestrais, de onde vieram e para o qual voltarão. Uma visão predominantemente animista prevalece nessas culturas, assim como nas literaturas delas resultantes.

A diversidade das cosmogonias desses povos étnicos e o limitado espaço de aqui dispomos, nesta introdução, além da observância do recorte deste dossiê, impõe uma apresentação sintética sem ignorar, entretanto, as inúmeras leituras que da temática proposta podem advir, ainda mais se considerarmos as relações entre literaturas, cosmogonias e imaginários, cujos espaços de saberes que se entrecruzam são dinâmicos, heterogêneos e em constantes movimentos criativos. Portanto, este dossiê pretendeu reunir trabalhos, cujos objetivos põem, sob as mais variadas facetas teóricas e metodológicas, em análises, reflexões, debates ou discussões, diferentes textos literários, teóricos, filosóficos, críticos, escritos por indígenas, africanos, afro-brasileiros ou não, nos quais as suas cosmovisões e seus diferentes imaginários e outras criações literárias, sejam protagonistas nos mais variados territórios e contextos sociais, históricos e culturais.

Em “A linha, o manto, o cravo, o barco, o arco, a flecha, a lança, a flor, a máscara e a cabeça: a matéria enquanto gesto poético-performático ancestre”, de Ana Pedrosa (UFBA), analisa-se com fluidez e leveza a poética-performance do sergipano Arthur Bispo do Rosário que, entre os limites da arte e da loucura, trouxe um empreendimento artístico ancestre, como agenciamento de letramentos de (re)existência negra, cujas matrizes conceituais atravessam as perspectivas hegemônicas da colonialidade.

Instigante é o artigo "Como Davi Kopenawa, sendo um contador de histórias, dá conselhos, ou senão, ensina arte de narrar a Walter Benjamin”, de Brena Moura (UEPA), 
cuja discussão coloca um confronto epistemológico entre as ideias da arte de narrar na modernidade, como propostas pelo escritor alemão Benjamin, e os saberes narrativos do xamã yanomami Davi Kopenawa, originários de cosmovisões ancestres. Em seus relatos cosmogônicos, este ancião evidencia a preponderância do texto criativo, imaginativo, contra a lógica hegemônica capitalista, repleta de ponderações teóricas, iluminadoras, pontuais, as quais podem limitar outras visões do mundo. Um convite ao debate entre criatura x crítico. Como a fé sem as obras é morta, devemos de nos aproximar da análise crítica, mas reconhecer, sobretudo, a primazia potencial do texto criativo. A articulista encara o pensamento indígena de Davi Kopenawa como o ponto de partida para uma teoria narrativa que vai na contracorrente da cultura eurocêntrica incapaz de, muitas vezes, abrir espaço para um diálogo intercultural e para a escuta das vozes à margem.

Na sequência, as (os) autoras(es) Danielle Mendes Sousa (UNIFESSPA) et al. trazem em destaque uma análise da personagem Iara, ser insólito que dizem habitar os rios amazônicos, presente no conto "A Iara do Rio Santana" (2019), do paraense Walcyr Monteiro (1940-2019). Elas(es) baseiam-se nas categorias ficcionais do gótico, insólito ficcional e fantástico, como modo, sob os aportes teóricos de Noël Carroll, Flávio Garcia, Marisa Gama-Khalil, entre outros. Vale dizer que, munidas(os) de um aporte teórico ocidental, Danielle Mendes et al. entendem Iara como sendo uma personagem plurifacetada de uma lenda que faz parte do imaginário folclórico brasileiro. O texto ressalta a existência de diversas representações de Iara na cultura popular, as quais, contendo aspectos indígenas e europeus, foram sendo construídas pelas estreitas relações entre a oralidade e a escrita. $\mathrm{Na}$ narrativa de Walcyr Monteiro, a história dessa figura feminina apresenta uma esfera do horror, como força sobrenatural, causando terror e medo no imaginário humano.

$\mathrm{O}$ artigo "O Método Arquetipológico e o Estudo das Literaturas Indígenas e Afrodiaspóricas", de autoria de Heliene Rosa da Costa (REMEUDI/PMU-SME), abre as discussões deste número da revista Téssera, propondo uma leitura de textos escritos por mulheres indígenas e afrodescendentes, a partir dos subsídios do método de análise arquetípica durandiana, como forma de questionar o silenciamento preconceituoso que encobre suas manifestações literárias. A articulista concentrou-se nas escritoras Graça Graúna, Lia Minápoty, Márcia Kambeba, Conceição Evaristo, Cristiane Sobral e Kuisan de Oliveira, cujas poéticas recorrem às cosmovisões ancestrais, inspiradas nos laços sagrados 
femininos, com os propósitos de se fortalecerem enquanto mulheres indígenas ou negras que subvertem a lógica hegemônica e machista do sistema cultural nacional.

O texto de Lidiane Neves (GELLAMA), apreciando o livro Sol de Feira (1973), de Luiz Bacellar, apresenta a poetização do cotidiano por meio do imaginário despertado pelas frutas em exposição. É uma interessante leitura com suporte teórico em Umberto Eco (Seis Passeios no bosque da ficção), bem como em dicionários de Gheerbrant, Brunel, entre outros, dialogando ainda com Ivete Walty e com Antonio Candido.

Randra Barbosa Barros (PUC-RJ) propõe, em "O povo filho das águas: entre narrativas verbais e visuais Pataxó", uma excelente imersão reflexiva pelo imaginário cosmogônico do povo Pataxó por meio da leitura da narrativa Txopai e Itôhã (1997), escrita pelo cacique, educador e artista Kanátyo Pataxó (1961-) em co-autoria com a contadora de histórias, Apinhaera Pataxó, e ilustrada pelos integrantes de seu povo de origem da aldeia de Barra Velha na Bahia. Atenta aos aspectos verbais e visuais do texto literário, e sempre em diálogo com as produções bibliográficas de autoria indígena, Randra Barros consegue captar o complexo campo da cosmovisão indígena Pataxó, o qual, presente nas memórias ancestrais, conecta fundamentalmente o ser humano à natureza em seu vínculo vital com a água.

Ricardo Mendes Mattos estuda as conexões entre jongo, entendido como um complexo ritual religioso afro-brasileiro, e o imaginário mítico, levando em consideração o papel da memória oral que permite a comunicação com a ancestralidade para uma experiência corporal, gestual e verbal pela qual se luta por uma liberdade autêntica dos negros. O autor preocupa-se em enfatizar o caráter político dessa mítica manifestação afrodescendente, realizada sobretudo em território marginal, em uma travessia espiritual entre Brasil e África pela madrugada, com a qual se luta contra os opressores.

No último texto deste número, intitulado "O feminino maldito em Anticristo, de Lars Von Trier”, de Jessé Antunes Torres, que se encontra na seção livre da revista, há um estudo acurado sobre as produções tecnológicas do imaginário mobilizadas pelo filme do dinamarques Lars Von Trier enquanto eficaz operador de uma lógica simbólica e imagética na medida em que trabalha a temática da morte e os seus entrecruzamentos com as figurações do inconsciente. Para tanto, em sua investigação, Torres privilegia a mitocrítica, sob a perspectiva de Gilbert Durand (1921-2012), mas, como ressalta, prefere não se deter apenas a ela. Os destaques interpretativos dados ao feminino e a suas imagens são o ponto forte do 
artigo, porque conseguem exprimir uma preocupação sensível ao perceber os espaços mágicos, subversivos, subjetivos, simbólicos, míticos ocupados pela protagonista do filme "que procura outras maneiras de ser mulher que não nos papéis de mãe e de esposa submissa".

Em suma, este dossiê conseguiu acolher diversas(os) autoras(es) e textos, os quais, em contexto teórico e analítico bastante heterogêneo - e aberto ao diálogo produtivo -, buscaram fortalecer os estudos literários e de outras artes, bem como valorizar as cosmovisões e os imaginários indígenas, africanos e afro-brasileiros tão historicamente atacados e subjugados pela colonialidade do pensamento cultural e literário hegemônico. A expectativa é de que esses saberes aqui em circulação encontrem nas leitoras e nos leitores os espaços do respeito e da reflexão, elementos fundamentais para que os compromissos com o bem-estar do ser humano e da natureza prevaleçam e se confirmem nos mais distantes campos da imaginação.

Boas leituras!

\section{Referências}

ELIADE, Mircea. Mito e realidade. 6. ed. São Paulo: Perspectiva, 2006

JECUPÉ, Kaká Werá. A terra dos mil povos: história indígena brasileira contada por um índio. Ilustrado por Taisa Borges. 2 ed. São Paulo: Peirópolis, 2020.

KRENAK, Ailton. Ailton Krenak. In: Cohn, Sérgio; Kadiwèu, Idjahure (orgs.). Tembetá: conversas com pensadores indígenas. Rio de Janeiro: Azougue Editorial, 2019. p. 11-51.

KOPENAWA, Albert; BRUCE, Albert. A queda do céu: palavras de um xamã yanomami. Trad. Beatriz Perrone-Moisés. São Paulo: Companhia das Letras, 2015.

MINDLIN, Betty. O primeiro homem e outros mitos dos índios brasileiros. São Paulo: CosacNaify, 2001.

PRANDI, Reginaldo. Mitologia dos Orixás. Ilust. Pedro Rafael. 1 ed. São Paulo: Companhia das Letras, 2001.

POTIGUARA, Eliane. A terra é a mãe do índio - Nhándecy. GRUMIN (Grupo Mulher Educação Indígena). Minas Gerais: PUC-Minas Gerais, 1989. 
C. A. Melo; Z. Duarte

O imaginário mítico indígena e africano - cosmogonias e outras criações imaginárias - na literatura e nas artes.

POTIGUARA, Eliane. Eliane Potiguara. In: Cohn, Sérgio; Kadiwèu, Idjahure (orgs.). Tembetá: conversas com pensadores indígenas. Rio de Janeiro: Azougue Editorial, 2019. p. 104-144.

ROCHA, E. O que é mito? São Paulo: Brasiliense, 2006. 